TITLE:

\title{
The Passing of Professor Toshisada Nishida Lamented
}

$\operatorname{AUTHOR}(\mathrm{S}):$

Kawai, Masao

\section{CITATION:}

Kawai, Masao. The Passing of Professor Toshisada Nishida Lamented. Pan Africa News 2011, 18(special issue): 1-2

ISSUE DATE:

2011-09

URL:

http://hdl.handle.net/2433/147295

RIGHT:

Copyright (C) Pan Africa News. 


\section{Pan Africa News}

The Newsletter of the committee for the care and Conservation of Chimpanzees, and the Mahale Wildife Conservation society

ISSN 1884-751X (print), 1884-7528 (online) mahale.main.jp/PAN/

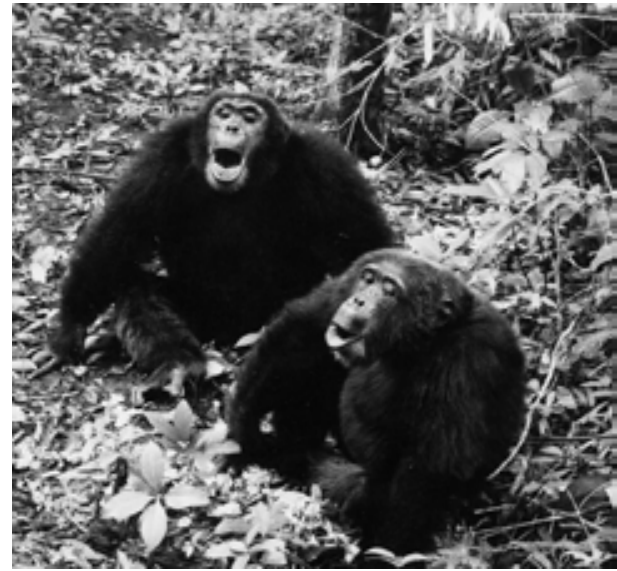

VOL. 18, special issue

\section{P. A. N. EDITORIAL STAFF}

\section{Chief Editor:}

Kazuhiko Hosaka, Kamakura Women's University, Japan

\section{Deputy Chief Editor:}

Michio Nakamura, Kyoto University, Japan

\section{Associate Editors:}

Christophe Boesch, Max-Planck Institute, Germany

Jane Goodall, Jane Goodall Institute, USA

Tetsuro Matsuzawa, Kyoto University, Japan

William C. McGrew, University of Cambridge, UK

John C. Mitani, University of Michigan, USA

Vernon Reynolds, Budongo Forest Project, UK

Yukimaru Sugiyama, Kyoto University, Japan

Richard W. Wrangham, Harvard University, USA

Takeshi Furuichi, Kyoto University, Japan

\section{Editorial Secretaries:}

Noriko Itoh, Kyoto University, Japan

Koichiro Zamma, Great Ape Research Institute, Hayashibara, Japan Agumi Inaba, Japan Monkey Centre, Japan

\section{Instructions for Authors:}

Pan Africa News publishes articles, notes, reviews, forums, news, essays, book reviews, letters to editor, and classified ads (restricted to non-profit organizations) on any aspect of conservation and research regarding chimpanzees (Pan troglodytes) and bilias (Pan paniscus). Contributors are requested to write in English and the papers except forums, reviews and essays should usually be 1,500 words or less. Articles and notes will be peer-reviewed by at least one appropriate expert on request of the $P A N$ editorial staff.

Manuscripts should be formatted as DOC or RTF files and submitted by e-mail to: pan.editor@gmail.com

Photos and figures should be formatted as JPEG or GIF files and sent separately by e-mail attachments.

$P A N$ is published twice a year in June and December. Deadline for manuscripts is one month before publication (i.e. the ends of May and November).

\section{The Passing of Professor Toshisada Nishida Lamented}

\section{Masao Kawai \\ Professor Emeritus, Kyoto University, Japan}

When I heard the news of Nishida-san's passing, I was overwhelmed by grief. What a great loss! The word 'loss' came to me in two senses. First, I believed that he himself regretted the 'loss' of his own life deeply. I heard that he was brooding over several writing plans. He wanted to produce some original papers using his enormous data

\section{Editorial}

This special issue of Pan Africa News is dedicated to Professor Toshisada Nishida who passed away in June 2011. As readers may be aware, he was the first editor-in-chief of $P A N$, and devoted his life to the study and conservation of wild chimpanzees. We asked those who knew him very well, both from Japan and overseas, to contrib-

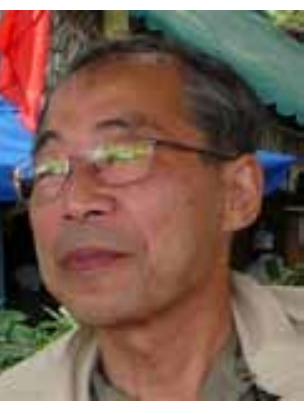
ute their memories of Professor Nishida. These people include senior and junior colleagues, friends, and Professor Nishida's students who have conducted research on chimpanzees at Mahale.

We were fortunate to have opportunities to accompany Professor Nishida in the field. He followed chimpanzees doggedly at Mahale for nearly 50 years. We learned a great deal about chimpanzees from him. We enjoyed being with him, admired him, sometimes were bit bewildered by what he said, and laughed a lot with him. Here, we share some recollections. These stories add to his legacy, and will inspire future research and our efforts to conserve chimpanzees.

We thank those who helped us translate some contributions originally written in Japanese to English. We are also indebted to Professors John C. Mitani and William C. McGrew, who read these translations and edited the English. about the chimpanzees he had studied for 50 years with all his heart. Furthermore, he was preparing to compile all his longtime accomplishments into a lifework Englishlanguage volume. I can hardly imagine how deeply he regretted having to go on his last journey without realizing such plans. However, he conquered the pain of cancer and completed "Chimpanzees of the Lakeshore: Natural History and Culture at Mahale" to be published at the end of this December by Cambridge University Press. I hope that this lessened his disappointment of not being able to write more.

Secondly, the 'loss' of Nishida-san meant a great loss to primatology not only for Japan but also for the world. 
His passing cannot be mourned too much. He was a pioneer in the study of wild chimpanzees. Since 1965, he maintained research at Mahale, Tanzania, and accumulated accomplishments unique to his team, rivaling another longtime chimpanzee researcher, Dr. Jane Goodall whose work at Gombe is well known. He published many excellent papers, for example, on patrilineal structure of chimpanzee society, political strategy among males, and scientific documentation of newly discovered cultural behaviors. He was awarded the Leakey Prize and the International Primatological Society Lifetime Achievement Award. In addition, he served as President of the International Primatological Society. These honors tell how highly he was esteemed internationally.

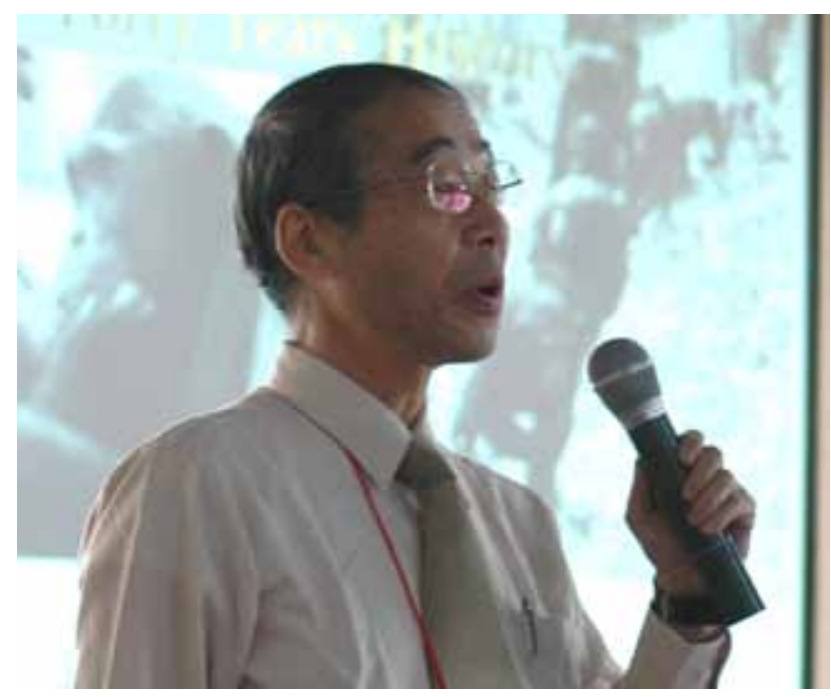

In 2004, he took up a new position as Executive Director of the Japan Monkey Centre (JMC). JMC is the place where Japanese primatology started and serves as a symbol for our discipline. I strongly recommended him as the best person for this position. The JMC hosts the World Primate Zoo and conducts museum activities such as social education, collection and preservation of materials, research, primate conservation, and publication of the international journal, Primates. Nishida-san, who had been eager to spread knowledge about primatology, took on his position energetically like a fish in water. Above all, his greatest achievement as Executive Director of the JMC was to enhance its international activities enormously. $\mathrm{He}$ advanced the research project for great ape conservation by the Ministry of Environment and set up the executive office of Great Apes Survival Project Japan Committee (GRASP-Japan) in JMC.

His strong mind commands my profoundest admiration and respect. He had to fight against a serious disease but successfully fulfilled his responsibilities as Executive Director of JMC, performed international activities, and continued to write vigorously. He trained many excellent students. I hope that they will collaborate in maintaining the chimpanzee research station at Mahale, and succeed as Nishida-san would have liked by advancing the project dynamically. May he rest in peace.

(English translation by Kazuhiko Hosaka)

\section{Tribute to Prof. Toshisada Nishida}

\section{Vernon Reynolds}

Oxford University, UK/Budongo Conservation Field Station

I first met Prof. Nishida ("Toshi" as we came to know him) on a visit to the Mahale Mountains chimpanzee project which I made in the late 1970s. I met up with my colleague Yuki Sugiyama in Dar es Salaam and we travelled across Tanzania to Kigoma. There we were supposed to meet a boat from the chimp project which would take us down Lake Tanganyika to Mahale. But it turned out that the boat's outboard motor was broken. We waited a few days during which we met Toshi and spent some time with him, talking about his work and the Mahale chimpanzees. Eventually I made it to the project where I met the team and the chimps. I did not know it, but I was quite seriously ill with hypothyroidism at the time and my lack of energy surprised the Japanese researchers, but they were kind enough to give me a slow and considerate field assistant to accompany me in the forest. I think we only met Toshi once during that trip, but owing to the thyroid problem I don't remember much about it.

Over the years, at conferences in Japan and elsewhere, I met Toshi again many times and was always impressed by his friendliness and total dedication to the cause of chimpanzees. I read his book on the Mahale chimpanzees, indeed it was given to us at one of those big IPS conferences in Japan.

Another occasion I remember well was in Paris, where a number of chimpanzee project leaders took part in a meeting at UNESCO headquarters to try and create a new category of "World Heritage Species", with the apes as the first species in that category. We had good discussions in which Toshi took a leading role. He was also good fun to be with in the little restaurants where we stopped during the days in Paris.

Above all he will be remembered for his work on the chimpanzees of the Mahale Mountains, a field site he set up and which continues to thrive at the present time. Only those who have set up a field site know how much work is involved, and Toshi was an indefatigable field worker who set the highest standards for his students. I recall him as a man who had that rare quality of acute observation without which it's impossible to be an astute fieldworker, and finally as a man who combined a firmness of purpose with a friendly outlook and disposition.

We at Budongo are all sorry to lose him, and send our condolences to his family.

\section{Reminiscences of Our Student Days}

\author{
Kosei Izawa \\ Professor Emeritus, Miyagi University of Education, Japan
}

For seven years (1961-1968), after I was admitted to the Department of Zoology, Faculty of Science, Kyoto University, until I completed my doctoral course, Nishidasan and I were together in the same lab, as if we had eaten out of the same pot all the time. During that period, 